\title{
Projeto Patrino: um Aplicativo com Inteligência Artificial Aplicada no Gerenciamento de Bancos de Leite Humano
}

\author{
Sebastião Henrique Nascimento Santos, Eduardo Silva Vieira, Davi Viana dos \\ Santos, Arthur Costa Serra, Layane Menezes Azevedo, Pedro H. Carvalho Vieira \\ Universidade Federal do Maranhão (UFMA) - São Luís - MA - Brasil \\ \{sebastiaohns, edusvieirap, arthurserra10, layanemazevedo, pedeziq2\} @gmail \\ .com, davi.viana@lsdi.ufma.br
}

\begin{abstract}
Human milk banks form an extensive and complex network that provides essential services to the country that ensures that newborns and mothers can fully enjoy the benefits of breast milk. These centers serve millions of people annually using thousands of liters of human milk. Thus, in this work we aim to create a breast milk distribution management system, using artificial intelligence to predict shortages, the use of geographic information to help locate human milk centers and provide essential information about motherhood and breastfeeding.
\end{abstract}

Resumo. Os bancos de leite humano formam uma rede extensa e complexa que levam a todo país serviços essenciais que garantem que recém-nascidos e mães possam usufruir plenamente dos beneficios do leite materno. Esses centros atendem milhões de pessoas anualmente utilizando milhares de litros de leite humano. Assim, nesse trabalho visamos à criação de um sistema de gestão da distribuição de leite materno, usando inteligência artificial para prever desabastecimentos, o uso de informações geográficas para ajudar na localização de centros de leite humano e levar informações essenciais sobre maternidade e amamentação.

\section{Introdução}

O leite materno é a forma mais importante de alimentar e proteger recém-nascidos, já que possui os nutrientes necessários para garantir a saúde do ser humano ao longo de sua vida [Andreas et al. 2015], também protege as mães do câncer de mama e de útero. Os Bancos de Leite Humano (BLH) são uma estrutura de apoio fundamental para recém-nascidos e mães que encontram dificuldades na amamentação.

O BLHWeb é uma ferramenta para Gestão e Credenciamento dos Bancos de Leite Humano usado pela Rede de Banco de Leite Humano (rBLH) [Silva et al. 2009], porém seu uso não é obrigatório. Quando usado, o sistema faz o controle dos processos de um BLH, fazendo o registro dos doadores, receptores e dos produtos, além de outras funções.

Embora a rBLH tenha contribuído enormemente para o propósito que foi criado, é essencial a criação de um sistema que permita gerenciar essa gama de informações de maneira mais eficiente do que a atual, além de aproximá-la dos seus usuários. Dessa forma, propomos a criação de um sistema de gestão para distribuição de leite materno 
usando inteligência artificial para prever desabastecimentos e um sistema com informações geográficas para ajudar na localização de centros de leite humano.

\section{Descrição do Sistema}

A partir do uso de Inteligência Artificial será desenvolvido um sistema para analisar o histórico dos insumos, serviços e usuários dos BLH, a partir dos dados disponível na base pública criada pelo Ministério da Saúde e da Fundação Oswaldo Cruz, para que se possa apresentar diretrizes ideais a ser seguidas. Com isso pretendemos levar as unidades de atendimento um pleno funcionamento, em que se poderão coordenar campanhas de doação com antecedência para evitar o desabastecimento. Nesse sentido, o registro das doações ou retirada de leite nos centros de distribuição são essenciais para possibilitar que profissionais possam gerenciar o estoque de maneira eficiente.

Além disso, o sistema também irá permitir que os usuários possam localizar os centros de distribuição mais próximos de sua residência e verificar a disponibilidade de leite materno disponível tornando o sistema mais transparente. Por fim, será apresentada a população técnicas para a coleta e a doação de leite, assim como os melhores recipientes para esta tarefa e ainda informações sobre a maternidade e a importância da amamentação.

\section{Contribuições}

Iremos utilizar o framework React Native para desenvolver aplicações mobile nativas multiplataformas e a biblioteca JavaScript OpenLayers, para criação e exibição de mapas, permitindo que os usuários possam localizar os centros de distribuição de leite mais próximos de suas residências. Também usaremos a Inferência Bayesiana para estimar o momento e quantidade ideal de estoques nos centros de distribuição levando em consideração o estoque atual e a demanda por leite em uma determinada região.

Assim, iremos criar uma aplicação que poderá ser usada por todas as instituições que fazem parte da Rede de Banco de Leite Humano. Além disso, iremos desenvolver e validar técnicas de computacionais aplicadas na administração dos BLHs.

\section{Considerações Finais}

Com o desenvolvimento do sistema Projeto Patrino pretendemos fazer com que os Bancos de Leite Humano sempre estejam prontos para atender, evitar o desabastecimento de leite materno e levar informações essenciais para famílias de todo país. Iremos aplicar inteligência artificial e aprendizado de máquina para tornar o gerenciamento dos centros mais fácil e técnicas de usabilidade para apresentar as informações essenciais à população.

\section{Referências}

Andreas, N. J., Kampmann, B., and Le-Doare, K. M. (2015). Human breast milk: Areview on its composition and bioactivity.Early Human Development, 91(11):629 635. Special Issue: Neonatal Update 2015. 
Silva, J. H. F. d. et al. (2009). Inovações tecnológicas para uma estratégia de qualificação dos produtos e dos processos de trabalho em Bancos de Leite Humano: o sistema de gerenciamento BLHWEB. PhD thesis. 